\title{
The Design of the Hydraulic Model Tests Control System Based on Fuzzy Self-adaptive PID Algorithm
}

\author{
Xiafu Lv ${ }^{1}$ Yong Chen ${ }^{1}$ Yongping Zheng ${ }^{1}$ Xinglong Guo ${ }^{2}$ \\ ${ }^{1}$ Automation Institute, Chongqing University of Posts and Telecommunications, Chongqing 400065, P. R. China \\ ${ }^{2}$ Instrument Office, Chongqing Communications Research and Design Institute, Chongqing 400063, P. R. China
}

\begin{abstract}
The hydraulic model is an important experiment system for studying the hydrological characteristic of river, lake and choosing the engineering project of port, dam and sea-route. The quality of the hydraulic model tests mainly lies on the measurement and control technology. This paper presents a hydraulic model tests control system which employing industrial computer and PLC as main controller, tracking water level as measuring meter. The flux and water level double loop control architecture is employed. The fuzzy self-adaptive PID algorithm is employed to control water level and flux. This control system has been applied in practice hydraulic model tests.
\end{abstract}

Keywords: Hydraulic model, Water level, Flux, Fuzzy self-adaptive PID

\section{Introduction}

The hydraulic model, found by the proportion of actual watercourse parameters, is an important experiment system for studying the hydrological characteristic of river, lake and so on. In the design of sea-route, lough, wharf and dam, the hydraulic model test is the important basis and method for choosing the engineering project. For the measurement and control precise of flux and water level is high, the quality of the hydraulic model test lies on the test measurement and control technology level mainly [1]. Furthermore the hydraulic model test period is usually several days or weeks, the workload for long-time monitoring the water level and flow velocity is very big. Therefore in order to improve the hydraulic model test control precise and quality, shorten the test period and reduce the work intensity, an automatic measurement and control system for the hydraulic model test is needed urgently.

\section{The system requirement}

The requirement for this hydraulic model tests control system is applicable to rectangle and triangle weir. For various active bed and non-steady flow model tests, the water-infall side and tailgate can be controlled automatically according to different water slope, terrain and water volume. The hydraulic model tests control system is also required having such functions as model water flow rate control, water level measurement and tail gate control and so on. Each executor state and measured data should be displayed real-time. The system can process and store the test data automatically as well as output the test result in data form and curves.

The main technique parameters of the hydraulic model test control system as follows:

The water level measurement error: $\pm 0.1 \mathrm{~mm}$ (compared with the numerical value of the probe).

The water level control error: $\pm 1.5 \mathrm{~mm}$.

The flux measurement error: $\pm 0.1 \%$ (compared with the result of the water level from the probe).

The flux control error: $\pm 1.5 \%$.

The flux measurement range: $0-900 \mathrm{~L} / \mathrm{S}$.

The water level measurement range: $0-80 \mathrm{~cm}$.

The instrument continuous operation time: $\geq 35$ days.

\section{The control system principle}

In the hydraulic model tests, the control object is model water level and flow rate. This system employed the model water level and flow rate compound loop control configuration, that is the water level and flux in the model various position are measured and compared with the set values to obtain the water level and flux difference. Based on the water level and flux difference as well as the appropriate algorithm, the control signals are output to adjust the water inlet flux regulator and the tailgate motor respectively to control the model water level and flow rate. For unsteady water flow hydraulic model, the 


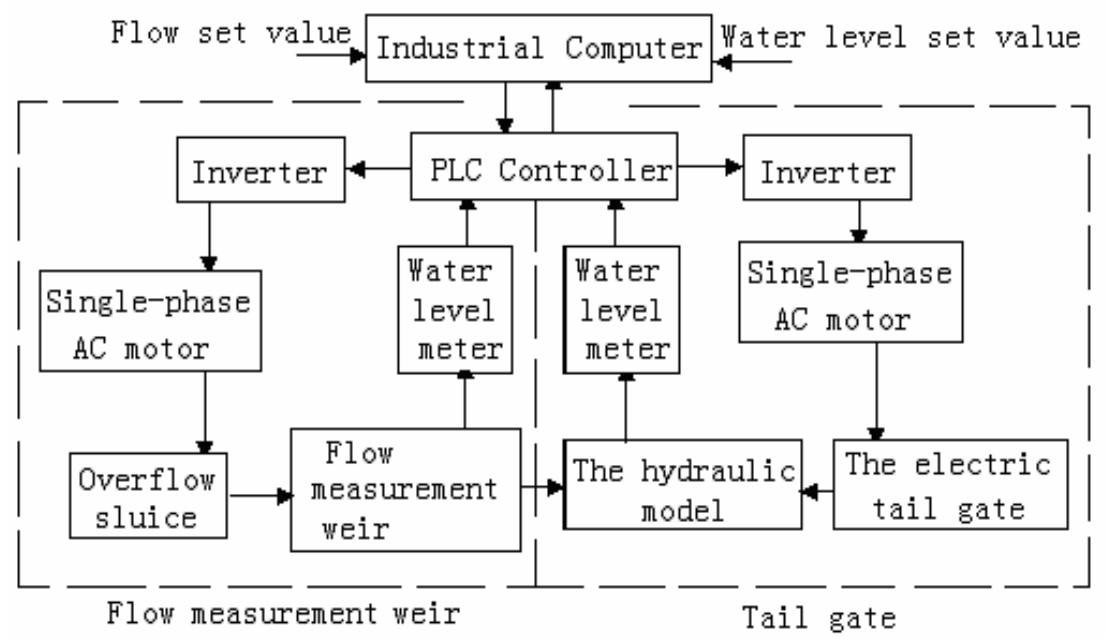

Fig. 1:The sketch block of the control system.

water level and flux set values are changed with time. The system employed master and slave control mode having upper and lower controllers. The upper controller is industrial computer and the lower is the programmable logic controller (PLC). The data and instructions are transferred between the upper and lower controllers by communication. Figure 1 is the sketch block of the control system.

\subsection{The flow rate control principle}

Electromagnetic flowmeter and electric control valve are the usual equipments for measuring and controlling the water flow in hydraulic model test. But these equipments are expensive and it is difficult to maintain. Meanwhile it is easy to bring overadjustment in water flow control. Therefore a flow measurement weir is employed to control the inflow water rate. The flow measurement weir made of the weir flume and plate is a device for measuring the water flow accurately. There is a relative accurate function relation between the weir discharge flow rate and the water level. The weir discharge flow rate can be calculated accurately based on the water level measured by the water level meter. The water inflow rate can be controlled accurately by adjusting the weir overflow sluice open position which relates with the difference of the flow actual measurement and setting value. If an unsteady flow rate is desired, the water level continuous measurement is needed.

There are various weirs based on different weir flume shape. The different function formulas are employed in different shape flow measurement weir. This hydraulic model test control system is adaptable to rectangle and triangle weir. To rectangle weir, the flow rate calculation formula is [2]:

$$
\begin{gathered}
Q=m_{0} B \sqrt{2 g} H^{1.5} \\
\mathrm{~m} 0=0.403+0.053 \mathrm{H} / \mathrm{a}+0.0007 / \mathrm{H}
\end{gathered}
$$

Here $\mathrm{Q}$ is water flow rate $\left(\mathrm{M}^{3} / \mathrm{S}\right), \mathrm{m} 0$ is flow rate coefficient, $\mathrm{B}$ is weir width $(\mathrm{M}), \mathrm{H}$ is water level height $(\mathrm{M}), \mathrm{a}$ is the upriver weir height. The above formulas can be applied in $\mathrm{H} \geq 0.025 \mathrm{M}$ and $\mathrm{H} / \mathrm{a} \leq 2$.

The flow rate calculation formula for triangle weir is [2]:

$$
Q=\frac{8}{15} \mu t g \frac{\theta}{2} \sqrt{2 g} h^{\frac{5}{2}}
$$

Here $Q$ is water flow rate $\left(\mathrm{M}^{3} / \mathrm{S}\right), \mathrm{H}$ is water level height (M), $\mu$ is flow rate coefficient, $\theta$ is the weir gate angle.

During the nonsteady water flowing discharged from the flow measurement weir, the weir plate is fixed and the weir water level height is measured by water level meter. The weir water level height approaches the setting value by automatically adjusting the weir overflow sluice open position.

\subsection{The water level control principle}

The model actual water level measured real-time by water level meter is compared with the water level setting value and the water level difference is obtained. An output signal, calculated out by a felicitous algorithm and the water level difference, is converted into the control signal which drives the actuator machine to adjust the model water level. In operation, the model water level and flow rate are measured continually to correct the control signal and make the water level approach the setting value. For nonsteady flow hydraulic model test, the water level and flow 
rate setting values are changed with time. Figure 2 is the water level control principle sketch.

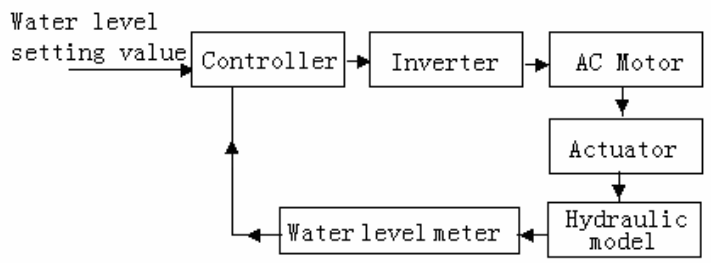

Fig.2: The water level control principle sketch

\section{The fuzzy self-adaptive PID algorithm design}

The fuzzy self-adaptive PID controller is mainly comprised of the parameters adjustable PID and fuzzy reasoning system. At the basis of conventional PID controller as well as the error " $E$ " and its rate " $\Delta \mathrm{E}$ " as input, the PID parameters $\mathrm{kp}, \mathrm{Ti}$, Td can be obtained by fuzzy reasoning method to satisfy PID parameters self-adjusting requirement at different time. The fundamental of the fuzzy self-adaptive PID controller is establishing the initial parameters and adjusting the parameters optimally using fuzzy reasoning and decision according to the practical response situation. Figure 3 is the structural block diagram of the fuzzy self-adaptive PID controller.

In this hydraulic model tests control system, the input of fuzzy reasoning is the model water level difference " $E$ " and its rate " $\Delta E$ ". The PID controller output is the parameters $\mathrm{kp}, \mathrm{Ti}, \mathrm{Td}$ respectively.

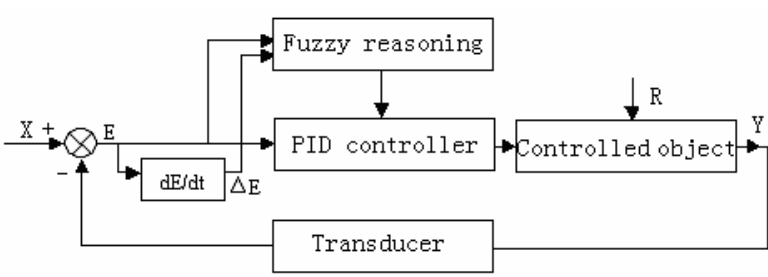

Fig.3: The structural block diagram of the fuzzy selfadaptive PID controller.

\subsection{The input/output parameters fuzzy description}

In this system the method presented by Mamdani is employed to fuzzy process the variable [3] to [4]. The error " $E$ " and its rate " $\Delta \mathrm{E}$ " as well as output variables are set up continuous variety at the zone $[-6,+6]$ and dispersed to form a discrete assembly including thirteen integer element $\{-6,-5,-4,-3,-2,-1,0,1,2,3$, $4,5,6\}$. At the same time the fuzzy state subset is defined as seven sections, that is $(\mathrm{PB}$ (positive big),
PM (positive middle), PS (positive small), Z (zero), NS (negative small), NM (negative middle), NB (negative big)\}. Suppose in the fuzzy process, the output variable $\mathrm{Kp}$ is $\mathrm{Up}$, Ti is $\mathrm{Ui}$ and $\mathrm{Td}$ is $\mathrm{Ud}$. The membership grade of the input and output variables is shown in table 1, table 2 and table 3 respectively.

In the hydraulic model test control system based on the fuzzy self-adaptive PID, the input variables are water level " $\mathrm{E}$ " and its rate " $\Delta \mathrm{E}$ ". The triangle function is employed as the membership grade formula. Figure 4 to 6 are the membership grate curves of the input and output variables.

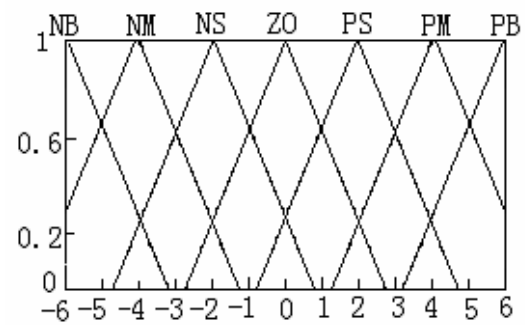

Fig. 4. Membership grate curve of the fuzzy input $\mathrm{E}$

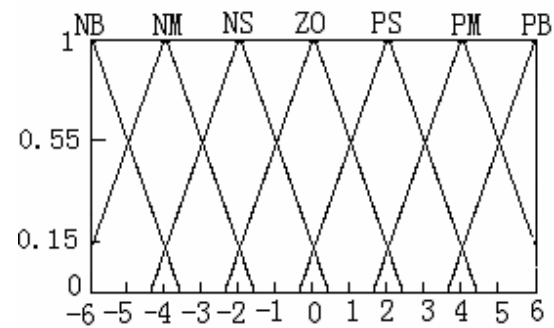

Fig. 5: Membership grate curve of the fuzzy input $\Delta \mathrm{E}$.

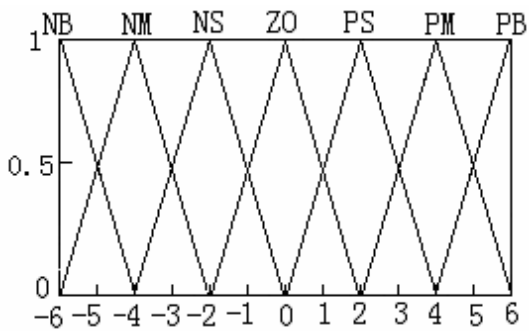

Fig. 6: Membership grate curve of the fuzzy output $U$.

\subsection{The fuzzy reasoning algorithm}

The fuzzy reasoning fashion is shown in figure 7 .

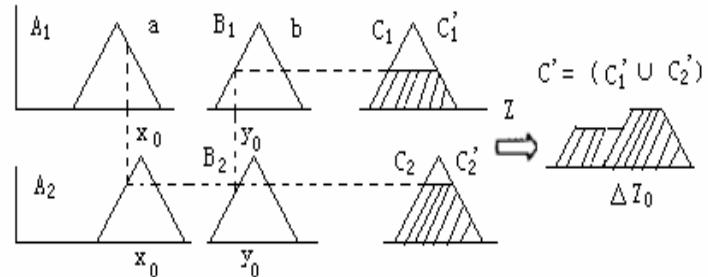

Fig. 7: Mamidani fuzzy reasoning algorithm. 
Rule 1: if $\mathrm{A} 1$ and $\mathrm{B} 1$, then $\mathrm{C} 1$.

Rule 1: if $\mathrm{A} 2$ and $\mathrm{B} 2$, then $\mathrm{C} 2$.

Rule n: if $\mathrm{An}$ and $\mathrm{Bn}$, then $\mathrm{Cn}$.
Precondition $\mathrm{x} 0$ and $\mathrm{y} 0$. Conclusion D.

\begin{tabular}{|l|l|l|l|l|l|l|l|l|l|l|l|l|l|}
\hline E & -6 & -5 & -4 & -3 & -2 & -1 & 0 & +1 & +2 & +3 & +4 & +5 & +6 \\
\hline PB & 0 & 0 & 0 & 0 & 0 & 0 & 0 & 0 & 0 & 0 & 0.2 & 0.5 & 1 \\
\hline PM & 0 & 0 & 0 & 0 & 0 & 0 & 0 & 0 & 0.2 & 0.5 & 1 & 0.5 & 0.2 \\
\hline PS & 0 & 0 & 0 & 0 & 0 & 0 & 0.2 & 0.5 & 1 & 0.5 & 0.2 & 0 & 0 \\
\hline Z & 0 & 0 & 0 & 0 & 0.2 & 0.5 & 1 & 0.5 & 0.2 & 0 & 0 & 0 & 0 \\
\hline NS & 0 & 0 & 0.2 & 0.5 & 1 & 0.5 & 0.2 & 0 & 0 & 0 & 0 & 0 & 0 \\
\hline NM & 0.2 & 0.5 & 1 & 0.5 & 0.2 & 0 & 0 & 0 & 0 & 0 & 0 & 0 & 0 \\
\hline NB & 1 & 0.5 & 02 & 0 & 0 & 0 & 0 & 0 & 0 & 0 & 0 & 0 & 0 \\
\hline
\end{tabular}

Table 1: Membership grade of fuzzy input E.

\begin{tabular}{|l|l|l|l|l|l|l|l|l|l|l|l|l|l|}
\hline$\Delta \mathrm{E}$ & -6 & -5 & -4 & -3 & -2 & -1 & 0 & +1 & +2 & +3 & +4 & +5 & +6 \\
\hline PB & 0 & 0 & 0 & 0 & 0 & 0 & 0 & 0 & 0 & 0 & .150 & 0.55 & 1 \\
\hline PM & 0 & 0 & 0 & 0 & 0 & 0 & 0 & 0 & 0.15 & 0.55 & 1 & 0.55 & 0.15 \\
\hline PS & 0 & 0 & 0 & 0 & 0 & 0 & 0.15 & 0.55 & 1 & 0.55 & 0.15 & 0 & 0 \\
\hline Z & 0 & 0 & 0 & 0 & 0.15 & 0.55 & 1 & 0.55 & 0.15 & 0 & 0 & 0 & 0 \\
\hline NS & 0 & 0 & 0.15 & 0.55 & 1 & 0.55 & 0.15 & 0 & 0 & 0 & 0 & 0 & 0 \\
\hline NM & 0.15 & 0.55 & 1 & 0.55 & 0.15 & 0 & 0 & 0 & 0 & 0 & 0 & 0 & 0 \\
\hline NB & 1 & 0.5 & 0 & 0 & 0 & 0 & 0 & 0 & 0 & 0 & 0 & 0 & 0 \\
\hline
\end{tabular}

Table 2: Membership grade of fuzzy input $\Delta \mathrm{E}$.

\begin{tabular}{|l|l|l|l|l|l|l|l|l|l|l|l|l|l|}
\hline U & -6 & -5 & -4 & -3 & -2 & -1 & 0 & +1 & +2 & +3 & +4 & +5 & +6 \\
\hline PB & 0 & 0 & 0 & 0 & 0 & 0 & 0 & 0 & 0 & 0 & 0 & 0.5 & 1 \\
\hline PM & 0 & 0 & 0 & 0 & 0 & 0 & 0 & 0 & 0 & 0.5 & 1 & 0.5 & 0 \\
\hline PS & 0 & 0 & 0 & 0 & 0 & 0 & 0 & 0.5 & 1 & 0.5 & 0 & 0 & 0 \\
\hline Z & 0 & 0 & 0 & 0 & 0 & 0.5 & 1 & 0.5 & 0 & 0 & 0 & 0 & 0 \\
\hline NS & 0 & 0 & 0 & 0.5 & 1 & 0.5 & 0 & 0 & 0 & 0 & 0 & 0 & 0 \\
\hline NM & 0 & 0.5 & 1 & 0.5 & 0 & 0 & 0 & 0 & 0 & 0 & 0 & 0 & 0 \\
\hline NB & 1 & 0.5 & 0 & 0 & 0 & 0 & 0 & 0 & 0 & 0 & 0 & 0 & 0 \\
\hline
\end{tabular}

Table 3: Membership grade of fuzzy output $U$.

Here A belongs to fuzzy assembly x, B belongs to fuzzy assembly y and $\mathrm{C}$ belongs to fuzzy assembly $z$. The reason result can be reached as $\operatorname{UDi}(z)=$ $\mathrm{Uc}(\mathrm{x} 0)^{\wedge} \mathrm{Uc}(\mathrm{y} 0)$. The final conclusion can be obtained by integrative reason result D1, D2, $\cdots$, and Dn. In this system, the max-min composition reasoning method is employed.

$$
U_{D}(z)=U_{D 1}(z) \vee U_{D 2}(z) \vee \bullet \bullet \bullet \vee U_{D n}(z)
$$

The fuzzy output from fuzzy reason should be translated into the non-fuzzy output for the process adjustment. The center of gravity (COG) method is employed as fuzzy inferential decision to defuzzify. The calculation formula as follow [5]:

$$
z_{0}=\frac{\sum_{i=1}^{n} u_{D}\left(z_{i}\right) g_{z}}{\sum_{i=1}^{n} u_{D}\left(z_{i}\right)}
$$


In the hydraulic model tests control system, the water level measured by water level meter and sent to the controller is compared with the set value, the water level difference " $\mathrm{E}$ " and its rate " $\Delta \mathrm{E}$ " are obtained. After the domain transform, the above " $E$ " and " $\Delta \mathrm{E}$ " are converted into the fuzzy variables " $E$ " and " $\Delta \mathrm{E}$ ". Thus the fuzzy output " $U$ " can be achieved by looking up the above table 3 . Then a reliable control parameter can be received by the corresponding quantitative factors.

\section{The system makeup}

The system consists of hardware and software. The hardware includes main controller, influent water flux measurement and control system (the flow measurement weir), the model water level measurement and control part and the model electric tail gate control and so on.

The main controller is comprised of industrial computer and programmable logic controller (PLC). As the upper controller, the industrial computer is responsible for the data calculation, storage, display and creating the data forms. The industrial computer receives the data from the lower controller and send the control instruction to it by the communication.
PLC is the lower controller which takes charge of the field data sample and control. By using this control configuration, when the upper controller is in trouble, the lower controller can still work normally and the stability and reliability of the system long time operation are insured. The LG MASTER $\mathrm{k}$ series model 120S PLC, which supports 64 modules and has two serial interfaces (RS232 and RS-485), is employed in this control system. Here the upper controller communicates with the lower controller by RS-232.

The influent water flux measurement and control system, namely the flow measurement weir, consists of water inflow part (water pump, valve and pipe), water level measurement part, water discharge part including flat overflow gate, inverter, alternating current motor, limit switch, motor bracket, screws and water return flume and so on. The water pump draws water into the flow measurement weir at a certain flow rate through the valve and pipe. A tracking water level meter and probe installed in the flow measurement weir measure the weir water level and send the measurement data to the controller. The controller calculates the weir water flow rate and compares it with the set value to control the weir flow rate by adjusting the overflow gate position.

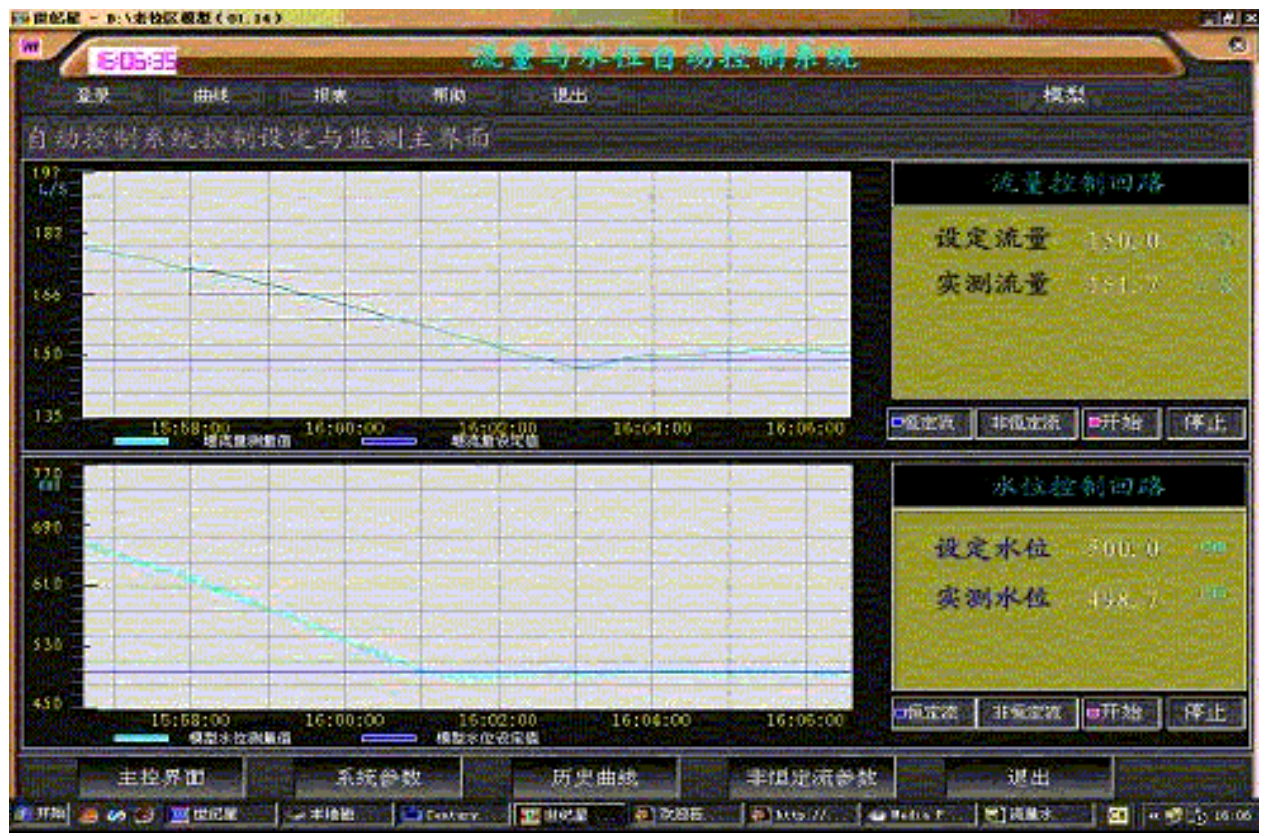

Fig. 8: The system software main interface.

The model water level measurement and control part is mainly tracking water level meters which are installed in the hydraulic model different position. Model LH-1 tracking water level meter, made in Wuhan research institute of water conservancy and hydroelectric power, is employed in this system. In operation the meter can automatically samples highest water level, lowest water level, time average water level and instantaneous level. The meter possess standard RS-232 and RS-485 serial interface and 
communicates with the controller by RS-485 serial interface.

The tracking water level meter installed nearby the tailgate and the tailgate control device constitute the tailgate water level close-loop control unit. The tracking water level meter measures the water level near the tailgate and sends the measurement data to the controller. Based on the water level difference between the measurement and set value, the controller output a corresponding signal to adjust the tailgate open and control the model downriver water level. A movable inclined tailgate is employed. The tail gate control device consists of the tail gate, inverter, alternating current motor, limit switch, joint, shaft, bracket, rope and hand wheel and so on.

The system software mainly completes the measurement data management such as data collection, calculation, storage, communication, print and forms build. Figure 8 is the system software main interface. For simplifying the software development and shortening the software development period, the Century Star configuration software is employed in this system. The Century Star configuration software has the advantages of multitask, multi-thread, fast sampling speed and high stability and possess perfect figure building function, ample data types as well as alarm, history trend curve building and so on.

\section{Experiment and conclusions}

This control system has been applied in the hydraulic model tests of Jingping hydropower station in Guizhou Province. The model water level measurement and control range is $40-75 \mathrm{~cm}$. The control response time is required less than 7 minutes. The water level control error is required less than $2 \mathrm{~mm}$. The conventional PID and fuzzy self-adaptive PID are employed to control the model water level respectively. Figure 9 is the experiment result curves.

The experiment result shows, compared with the conventional PID, the fuzzy self-adaptive PID has the advantages of fast response, small overshoot, short adjustment time to reach the equilibration, small oscillation near the equilibration and high reliability. Only by a little modulation, this control system can be applied in various hydraulic model tests.

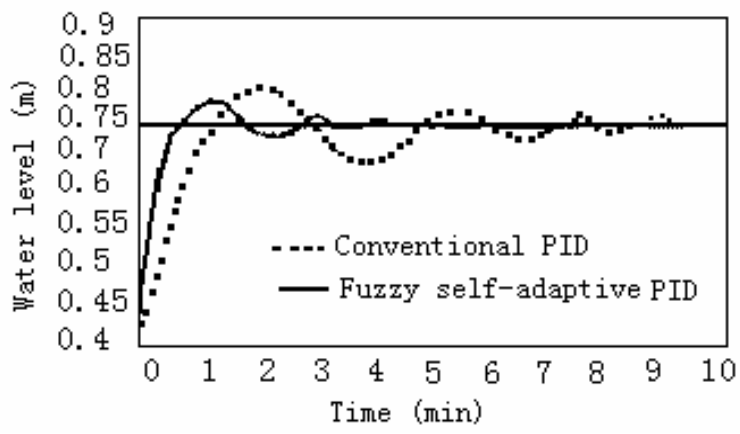

Fig.9: The experiment result curves.

\section{Acknowledgement}

This work is supported by Natural Science Foundation Project of CQ CSTC.

\section{References}

[1] J. Kuang, W.M. Li and B. Liu, The Study on Hydraulic Model Test Importance in the Small Hydropower. Water Conservancy Science and Technology and Economy, 12(9): 592-593, 2006.

[2] J.G Wu, Digital Weir. Journal of Hehai University, 28(2): 85-87, 2000.

[3] Y.Sh. Li and J. Li, Fuzzy Control Theory and its Application in Process Control. CA: National Defnse Industry Publishing Company, 1993.

[4] J.F. Han and Y.H. Li, Fuzzy Control Theory. CA: Chongqing University Press, 2003.

[5] Z.H. Xu, D.M. Jin and Zh. J. Li, Design of an Analog Fuzzy Logic Controller. RESEARCH \&PROGRESS OF SSE, 26(3):410-414, 2006. 